University of Nebraska - Lincoln

DigitalCommons@University of Nebraska - Lincoln

USING A RAPID PROTOTYPING MACHINE IN THE INTEGRATED KINEMATICS, DYNAMICS, AND MACHINE DESIGN LAB

Wieslaw M. Szydlowski

University of Nebraska-Lincoln, wszydlowski1@unl.edu

Follow this and additional works at: https://digitalcommons.unl.edu/mechengfacpub

Part of the Mechanical Engineering Commons

Szydlowski, Wieslaw M., "USING A RAPID PROTOTYPING MACHINE IN THE INTEGRATED KINEMATICS, DYNAMICS, AND MACHINE DESIGN LAB" (2001). Mechanical \& Materials Engineering Faculty Publications. 50.

https://digitalcommons.unl.edu/mechengfacpub/50

This Article is brought to you for free and open access by the Mechanical \& Materials Engineering, Department of at DigitalCommons@University of Nebraska - Lincoln. It has been accepted for inclusion in Mechanical \& Materials Engineering Faculty Publications by an authorized administrator of DigitalCommons@University of Nebraska Lincoln. 
Session S2E

\title{
USING A RAPID PROTOTYPING MACHINE IN THE INTEGRATED KINEMATICS, DYNAMICS, AND MACHINE DESIGN LAB.
}

\author{
Wieslaw M. Szydlowski ${ }^{\prime}$
}

\begin{abstract}
According to a recent trend, two different labs the Machine Design lab, and Kinematics, and Dynamics lab are combined into one integrated lab. The time students spend on their projects is halved. To save the quality of undergraduate education, an ew methodology has to be developed. The paper explains the methodology developed by the author while teaching the integrated Kinematics, Dynamics, and Machine Design Lab (MECH 488) at the Mechanical Engineering Department of the University of Nebraska-Lincoln.

The objective of the aforementioned lab is to teach the students, who have no design experience, how to select proper tools (from kinematics, dynamics, and machine design), and how to apply these tools in designing reliable and machinable parts. In this lab, the students actually make the parts using a rapid prototyping machine.
\end{abstract}

Index Terms - Design process, integrated design and kinematics lab, rapid prototyping machine.

\section{INTRODUCTION}

Many ME departments are currently looking for effective ways to reduce the students' course work and teaching load on the faculty, without compromising the quality of undergraduate education. In the past, courses such as Kinematics and Dynamics of Machinery, and Elements of Machine Design, were taught with separate 3-hour labs during which students worked on mini-projects illustrating the most important topics. According to the recent trend, when the labs are combined into one, the time the students spend on the projects is halved. Can the quality of undergraduate education still be maintained? It turns out that the situation can be quite advantageous. The combined lab may be successfully used to teach the students an integrated approach to design, with elements of both courses concurrently applied to engineering projects -- with greater emphasis on the big picture. Because of the shorter time, the selection of topics for the future projects is of great importance. The integrated Kinematics, Dynamics, and Machine Design lab (MECH 488) may be taken by the student after completing two prerequisite courses: Kinematics and Dynamics of Machinery, and Design of
Machine Elements. Due toi ndividual programs, some students may take this lab with a delay of one semester. The new lab may come a year and a half later than the course in kinematics, and much later than that when it comes to statics, dynamics, and computer drafting. For this reason, a time has to be provided in the new lab to review important material. This paper describes the methodology developed by the author while teaching the integrated Kinematics, Dynamics, and Machine Design lab (MECH 488) at the ME department of UNL.

\section{OBJECTIVES}

The objective of the above-mentioned course is to teach mechanical engineering in an environment that simulates the real design process. In particular, the emphasis of the course is on the selection of the proper tools from various branches of engineering science: statics, kinematics, material science, machine design, etc., as well as to awake the students' awareness of other aspects of design like ergonomics, reliability, and the appearance of the product. The students taking the course should get some training in modern engineering software, such as CAD, FEA, and Working Model. Special care should be taken to teach the students to design easily manufactured parts. Writing short and clear technical reports brings the list of the subjects $s$ tudied in the course to an end. The students work on individual projects or participate as members of a team. In the latter case, each team member has his or her own responsibilities. In this case, the final result of the project is one technical report, and fabrication of the parts on a rapid prototyping machine. The course carefully balances individual work and team work on an approximately 50:50 level.

The instructor meets an unusual challenge in this lab as he or she has to lay the foundations for good work in the capstone design courses which follow: MECH 446 and MECH 447 (Design I and II, respectively). The success of the students in this course (MECH 488) depends heavily of what they have learned (and remembered) inp revious courses like statics, kinematics, dynamics, machine design, and CAD. The experience teaches us that some important topics - like free-body diagrams, determination of inertia

Wieslaw M. Szydlowski, University of Nebraska-Lincoln, Mechanical Engineering Department, WSEC N 108, Lincoln, NE 68588, merdwms@engunx.unl.edu 
forces and torques, or principles of dimensioning of the drawings - fade with time. For this reason, well organized short review sessions have to be included in the teaching process.

To motivate students to work - and bring excitement to the classroom - a rapid prototyping machine should be used to make parts, so that the students can see the effects of their own work and learn from their errors. In a traditional course, all mistakes that a student makes are usually communicated directly to the student. When parts are made with errors, everybody knows who failed, a real life situation. As observed by the author, the students are much more motivated in this situation, and the loss of a part due to the error costs only a couple of dollars. The rapid prototyping machine also helps the students to develop important skills in visualizing three-dimensional parts for which two-dimensional drawings exist.

\section{RAPID PROTOTYPING MACHINE}

There is a large variety of rapid prototyping machines on the market. Extensive research was done to choose the machine which fits the requirements for the students' lab while remaining affordable. The most expensive machines are those that make parts out of resin which is cured with a laser beam. The parts made on these machines have very high precision and have significant strength. The parts may be assembled and operated under a considerable load. For example, a pair of snips used for cutting metal may be assembled and tested under a load to give a feel of the tool. These machines require specially fitted rooms to operate. Due to emission of unhealthy vapors, a special venting system must be installed. The productivity of these machines is slow. A user may have to wait several hours for the part to be completed. The current cost of these machines may be in the excess of 200,000 dollars. The cost of a single part may be significant as well - a pair of gears with a diameters of 2 inches may cost $\$ 500$.

There are also rapid prototyping machines which use a special paper to make the parts by laminating together sections of paper cut by the laser. The parts made by this method have a characteristic texture corresponding to the thickness of the paper used. The strength of the parts is much lower than that made of resin.

The third type of machines available are the 3-D printers. These machines make parts out of a special powder. The cheapest powder is a form of dextrose. These machines are relatively inexpensive (currently about $\$ 70,000$ ), environmentally safe (they can be installed in an office area), they are fast (student projects are made on average from 15 minutes to 2 hours). All systems necessary to make parts, like the de-powdering chamber, the electric oven, the wax bath, and the vacuum cleaner, come with the machine. Such

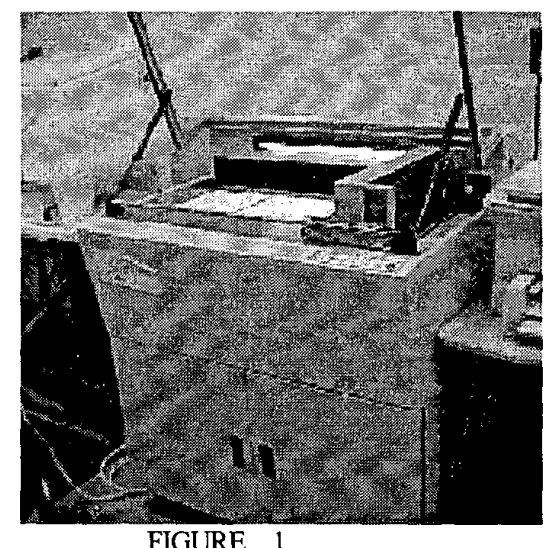

General view of Z-402 3-D printer. Visible areas of two pistons and the carriage with the printing head.

a machine that was finally selected for the MECH $488 \mathrm{lab}$ the Z 402 3-D printer, made by Z Corporation. It is shown in Fig.1. The cost of one cubic inch of the manufactured part is about $\$ 3$. The total cost of consumables for a section of 30 students in a semester is about $\$ 400$.

The machine has two "cylinders" of rectangular cross section. Each cylinder has a piston (bottom) controlled by the computer. At the beginning, the left piston is lowered and filled with the dextrose powder. The right piston is initially placed in the upper position. A solid drawing of the part prepared in STL format has to be loaded into the memory of the computer controlling the printer. The machine then transfers the powder from the left cylinder to the right one by spreading it with a reciprocating carriage. The thickness of the spread layers is very small (about 0.007 in.). The carriage has a printing head identical to that used in ink jet printers. On the return stroke the printing head sprays a special liquid (binder) to wet the area corresponding to the cross-section of the part which is being built. The liquid used in the spraying (the binder) acts as a glue. As the process continues, the part is built layer by layer. The finished part has to be removed carefully because in this stage it is quite fragile. To make it stronger, it has to be baked for a short time in an electric oven and then has to be immersed in a bath of molten wax. The wax infiltrates the part and makes it strong enough for handling and assembly. It is also possible to make the parts considerably stronger by infiltrating them with a special resin similar in properties to Superglue, instead of wax. In this form, the parts can be 
Session S2E

ground and painted. The machine is very easy to operate and maintain. The students learn to operate it after one 20 minute demonstration. Example of parts made by the Z-402 3-D printer are shown in Figs. 2 and 3.

\section{INTEGRATED KINEMATICS, DYNAMICS, AND MACHINE DESIGN LAB}

Ars longa vita brevis; if time is at a premium than careful choices have to be made as to what to cover in 15 (and often less) weeks of a semester. The author of the paper decided that it would be more advantageous to concentrate on basics rather than too broad of a scope. Out of the many subjects in kinematics and dynamics, the two that are of utmost importance are determination of the accelerations, and the inertia forces and torques. These skills combined with the ability to draw free body diagrams are sine qua non condition needed for successful stress analysis of machine parts.

The topics selected from MECH 343 (Design of Machine Elements) as the most important are: fatigue failure analysis, design of bolted and welded joints, and design of springs. The brushing up of other (also important) topics is left for the instructor teaching $\mathrm{MECH} 446$ (Design I). More complicated subjects are covered in MECH 447 (Design II).

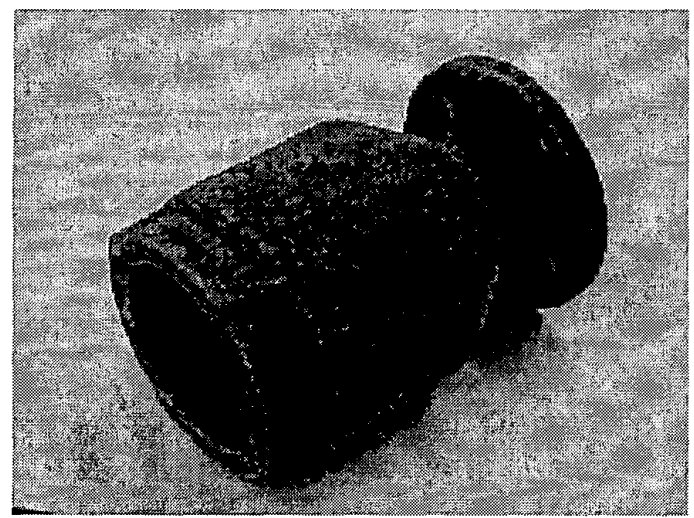

FIGURE 3

Another example of the part made by 3-D printer. Visible exrors that make this part impossible to machine and assemble.

Though all exercises in the course require hand calculations, the students are exposed to the modern tools of engineering, which are available via the departmental computer network. Three kinds of software are demonstrated in the course, and the students are required to work through tutorials prepared by the author. These include:
MicroStation Modeler v.5.0, for fast creation of solid drawings of the parts.

Working Model v3.0 software, for simulation of the operation of mechanisms.

- Algor v.12, Finite Element Analysis Software, for

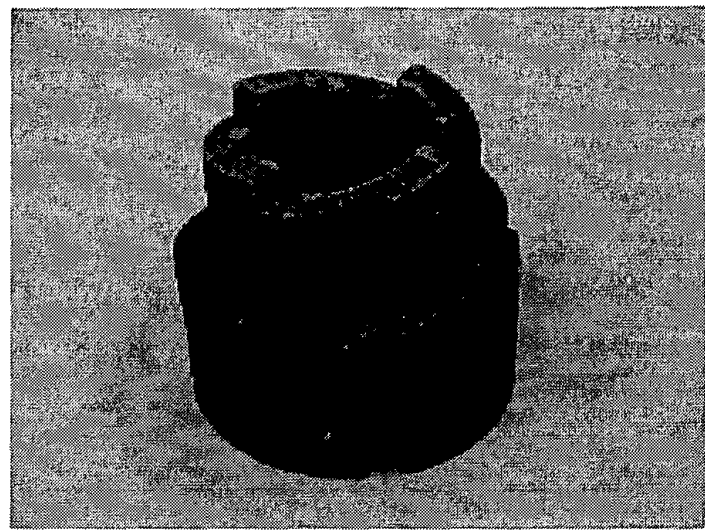

FIGURE 2

An example of a complicated part for an overload clutch. This part cannot be made by traditional machining. It is impossible to mill the ramp surfaces with a cylindrical cutter.

linear stress analysis.

The first two are familiar to the students from previous courses, although almost forgotten at the time when needed. Going through the tutorials does not consume much time. For example, working through the FEA Algor software takes 40 minutes for a good student, and an hour for the slowest. Because the average enrollment in the course is 30 students in four sections, it is possible to tutor students individually on an "as needed" basis.

Practice shows that almost all the students study tutorials (provided by the developer of the software) after the class. The willingness to learn how to use the FEA software comes from the general opinion that some employers look favorably upon graduates with this particular skill.

\section{EXAMPLES OF ASSIGNMENTS}

An example of an assignment in the discussed lab is shown in Table 1 . Thirty percent of all the assignments are changed each semester. The old assignments are re-circulated with 
changed numbers. Care is taken to ensure that all the assignments require a combination of two prerequisite courses, mainly kinematics and machine design. If possible, the assignments should lead the students to other parts of

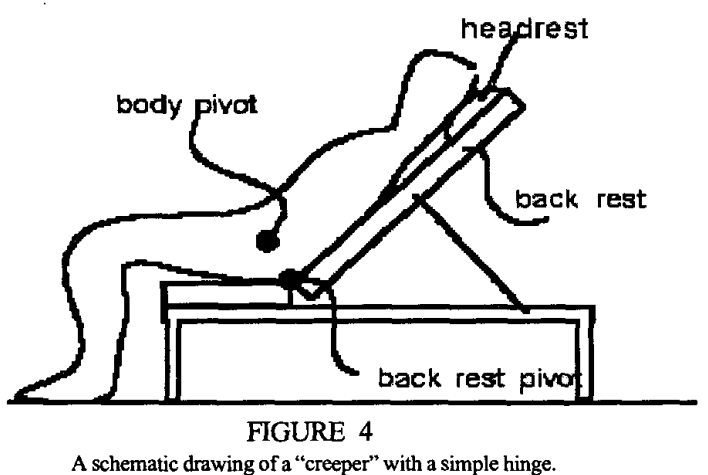

engineering knowledge important to the problem under consideration. A good source of ideas for the projects are [1], [2], issues of Mechanical Engineering Journal, catalogs of products like vane pumps and many other similar sources.

For example, in one of the team assignments a "creeper" for an aircraft mechanic had tob e designed with an adjustable back support and a head rest (Fig. 4). The students were asked to address the problem of the hinge for the back rest. Using a simple pin hinge creates a problem because the torso rotates about a different point (axis),

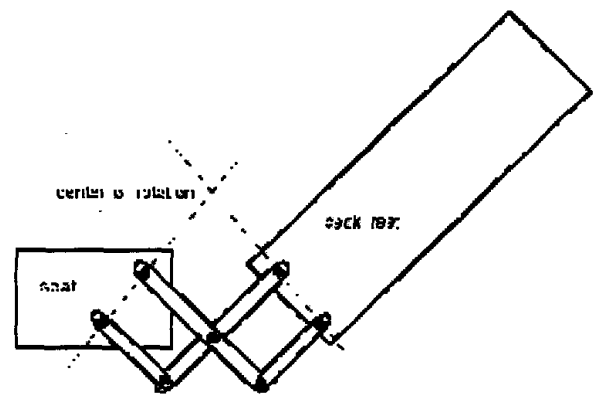

FIGURE 5

A linkage which allows the back rest to rotate about a distant axis.

located at the hip joint. For this reason, position of the head rest would have to be adjusted for every new position of the back rest. It is possible to design a hinge as a linkage, like the one shown in Fig. 5, which would allow rotation of the back rest about the axis of the hip joint.

At this point the instructor reviewed the kinematics concept of instant centers of rotation. To make students aware of other problems and help them to develop a "big picture", the instructor drew attention of the students to the role of ergonomics. As work continued, the instructor pointed to some safety problems with the linkage which may potentially have injured fingers accidentally inserted between the links. The ways to eliminate the pinch points may influence the final design. In this assignment, the use of Working Model software was very crucial. The students remembered the software from MECH 342 (Kinematics and Dynamics of Machinery). With the help of this software, they could quickly change dimensions of the links and location of the pivots and see the effect on operation of the mechanism. The students quickly noticed that the location of the gas spring supporting the back rest is not a trivial problem but in fact has a large effect on the range of motion of the back support. It also affects the pin reactions of the linkage. At that point students tried to perform an intuitive multifactorial optimization of the design. It turned out that version 3.0 of the Working Model software provided correct information about the magnitude of the pin reactions, but not the directions. The directions of the reactions had to be figured out by simple method of statics. The dimensions of the links (geometry of cross sections) were determined by hand calculation. After the solid drawings of the links were prepared with CAD software (each student worked on his or her own link), they were imported into the FEA Algor software and properly loaded with forces obtained from Working Model. The Finite Element Analysis was a part of the assignment where the instructor worked with individual students to make sure that the links were properly constrained.

Making the parts of the linkage was the last - and most exciting - part of the assignment. Each student saved the file representing his or her link in STL format and loaded it into the memory of the computer controlling the $Z-42$ rapid prototyping machine. All activities related to the preparation of the machine (settings of proper layer thickness, saturation, etc.) were done by the students.

Making parts with the rapid prototyping machine is an eye opening experience for the students When the parts are removed from the powder, one can understand from the remarks that they look different from what the students expected. This is a sign that at this stage the students cannot visualize the future part form a two dimensional drawing as well as experienced engineers can. One can frequently hear remarks such as: "I wish I made this wall thicker" or "this pin looks so thin". It is important to discuss errors at this stage of the project. It seems that mechanical engineering students have little knowledge about manufacturing processes in spite of courses taken in the past. Discussion of the feasibility of manufacturing the designed parts helps to fill this gap. 
Session S2E

TABLE 1

TYPICAL ASSIGNMENTSIN INITEGRATED KINEMATICS, DYNAMICS, AND MACHINE DESIGNLAB

\begin{tabular}{|c|c|c|c|c|c|c|}
\hline No. & Description of the assignment & $\begin{array}{l}\text { Intro } \\
\text { hrs }\end{array}$ & $\begin{array}{l}\text { work } \\
\text { hrs }\end{array}$ & Topics covered & & \\
\hline 1 & $\begin{array}{l}\text { Adjustment calculus. Application to } \\
\text { inspection of cam mechanism for a } \\
\text { snowmobile. }\end{array}$ & 1 & 5 & $\begin{array}{l}\text { 1. Numerical kinematics. } \\
\text { 2. Types of errors in measurements and } \\
\text { machining. } \\
\text { 3. Types of follower acceleration in cam } \\
\text { mechanisms. } \\
\text { 4. Structure of the technical report. }\end{array}$ & $\mathbf{T}$ & \\
\hline 2 & $\begin{array}{l}\text { Introduction to Finite Element } \\
\text { Analysis Algor software. } \\
\text { Design of a bracket for an overhead } \\
\text { conveyor system. }\end{array}$ & 3 & 6 & $\begin{array}{l}\text { 1. Rules for meshing and constraining. } \\
\text { 2. Pitfalls of FEA } \\
\text { 3. Weld calculations. } \\
\text { 4. Fluctuating load. } \\
\text { 5. Stress calculations by hand. } \\
\text { 6. Stress analysis by Algor software. }\end{array}$ & I & $\mathbf{R}$ \\
\hline 3 & $\begin{array}{l}\text { Analysis of bolted joint in a } \\
\text { connecting rod of an IC engine. }\end{array}$ & 1 & 2 & $\begin{array}{l}\text { 1. Review of kinematics of slider-crank } \\
\text { mechanism. } \\
\text { 2. Concept of equivalent masses. } \\
\text { 3. Calculation of inertia forces. } \\
\text { 4. Analysis of a bolted joint for fluctuating } \\
\text { load. Pre-load force, tightening torque, } \\
\text { Goodman diagram. }\end{array}$ & I & \\
\hline 4 & $\begin{array}{l}\text { Design of a spring for a cam } \\
\text { mechanism. }\end{array}$ & 0.5 & 2.5 & $\begin{array}{l}\text { 1. Acceleration of the follower. } \\
\text { 2. Conditions for the follower jump. } \\
\text { 3. Inertia forces. } \\
\text { 4. Design of a spring for infinite life. }\end{array}$ & I & \\
\hline 5 & $\begin{array}{l}\text { Design of a Geneva mechanism for } \\
\text { an assembly line conveyor. }\end{array}$ & 1 & 8 & $\begin{array}{l}\text { 1. Kinematics of a Geneva mechanisms } \\
\text { 2. Important details of design. } \\
\text { 3. Effective moment of inertia for the chain of } \\
\text { links. } \\
\text { 4. Stresses in a Geneva wheel: contact stress, } \\
\text { bending. } \\
\text { 5. Calculation of stresses by hand and by } \\
\text { FEA software. }\end{array}$ & $\mathrm{T}$ & $\mathbf{R}$ \\
\hline 6 & $\begin{array}{l}\text { Introduction to MicroStation Modeler. } \\
\text { Design of an overload clutch for a } \\
\text { production line. }\end{array}$ & 2 & 10 & $\begin{array}{l}\text { 1. Principle of operation of a overload } \\
\text { clutch. } \\
\text { 2. Building of a physical model of the clutch } \\
\text { to determine force of impact. } \\
\text { 3. Feasibility of machining of various parts. } \\
\text { 4. Stress calculations by hand and FEA } \\
\text { software. } \\
\text { 5. Design of springs and bolted connections. }\end{array}$ & $\mathrm{T}$ & $\mathbf{R}$ \\
\hline
\end{tabular}

Symbols used: I - individual report requested, $\mathrm{T}$-one report per team requested, $\mathrm{R}$ - parts made with rapid prototyping machine requested 


\section{MOST FREQUENT ERRORS}

In their initial attempts, the students make many errors (more than instructor initially expects). The main disadvantage of the rapid prototyping machine is that it can make impossible objects, which otherwise would be rejected by a shop manager. These errors essentially belong to three categories. It is important to familiarize the students with them in one of the first introductory lectures. These are as follows:

(A) Impossible to make shapes or features.

For example: some details of the machined part can be made by casting only, some features are impossible to make by milling with cylindrical cutters (see Fig. 2), some cavities, grooves, etc., are unaccessible and therefore impossible to machine.

(B) Some features can be machined with unjustified degree of. difficulty.

For example: small diameter, long blind holes with flat bottom, unnecessarily fancy contours of turned parts, features requiring special tools, holes in the .parts drilled at an acute angle to the surfaces, lack of filleted transitions between surfaces etc. (see Fig. 3).

(C) Interference between the parts caused by errors in dimensioning the drawings, or lack of spatial imagination. For example: the holes on mating parts are offset so the bolts cannot be inserted, the space behind the flange is so small that the required lengths of the bolts are too long to be inserted. Mechanism analysis performed on a "stick" model where the links take no room. Later in the model, the threedimensional links interfere and limit the range of motion or make it impossible (see Figs. 3 and 6).

Sometimes the students try to defend their part and claim that it can be made anyway. The author discovered that in such a case the best way to convince the student is to take him or her to the shop and consult the fabrication with the shop manager or machinist.

\section{CONCLUSIONS}

The integrated Kinematics, Dynamics, and Machine Design lab gives the ME students a better chance to understand the process of mechanical design than isolated exercises in individual courses like Kinematics and Dynamics of Machinery, or Design of Machine Elements. The use of a rapid prototyping machine provides the important link between theory and practice which was missing in traditional systems of engineering education. Working in small teams ensures activity for all the students. Making individual parts for the machine designed by the team develops the responsibility of individual members and shows the importance of information sharing within the team. The use

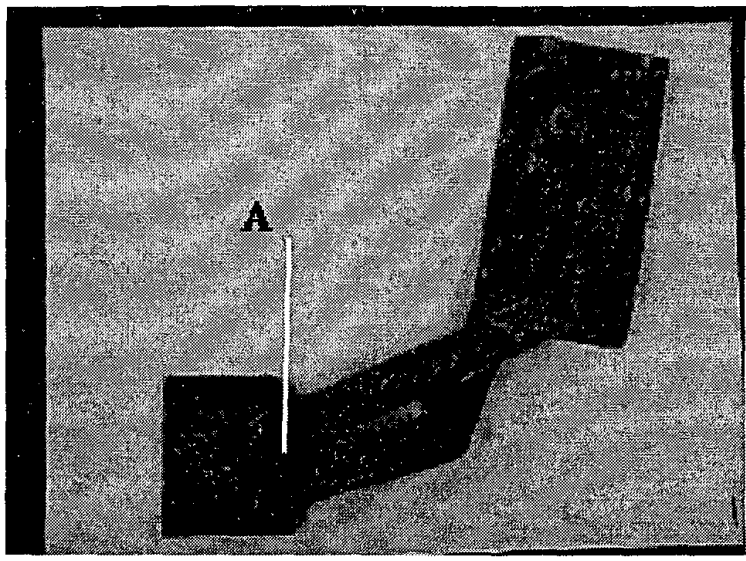

FIGURE 6

A linkage for the improved "creeper" made by the students. Too wide links cause binding at point $A$.

of the rapid prototyping machine brings the motivating factor, and additionally provides information about the feasibility of manufacturing, or provides a tangible proof that the machine can be assembled and operated. Discussion of design errors for existing parts explains manufacturing processes better than verbal lectures alone. There is a visible improvement in the quality of design work of the students in capstone design courses which follow.

\section{REFERENCES}

Jones, F. D., Ingenious Mechanisms for Designers and Inventors, vol. 1, 2, 3, 4. The industrial Press, NY 1951 Chironis, N. P., Mechanisms, Linkages, and Mechanical Control, McGraw-Hill Book Co., NY 1965 